\title{
Alzheimer's Disease and Intranasal Fluticasone Propionate in the FDA MedWatch Adverse Events Database
}

\author{
Steven Lehrer ${ }^{\mathrm{a}, *}$ and Peter H. Rheinstein ${ }^{\mathrm{b}}$ \\ ${ }^{\mathrm{a}}$ Department of Radiation Oncology, Icahn School of Medicine at Mount Sinai, New York, NY, USA \\ ${ }^{\mathrm{b}}$ Severn Health Solutions, Severna Park, MD, USA
}

Accepted 9 January 2018

\begin{abstract}
.
Background: Studies of Alzheimer's disease suggest that neuroinflammation or deranged brain wound healing may be a cause of some cases. But a placebo controlled study showed no effect at all on Alzheimer's disease of low dose oral prednisone after one year. Introducing the steroid directly into the hippocampus and rhinencephalon via the nose, as happens in hay fever subjects, could be more effective.

Objective: In the present study, we analyzed FDA MedWatch data for intranasal fluticasone propionate (Flonase) to determine the frequency of Alzheimer's disease as an adverse event reported after use of the medication.

Methods: Machine-readable data from MedWatch, including adverse drug reaction reports from manufacturers, are part of a public database. We used the online tool eHealthMe to query the database.

Results: By September 20, 2017, 35,221 people reported side effects to MedWatch after taking Flonase. Among them, 9 people $(0.03 \%)$ had Dementia Alzheimer's type. By October 3, 2017, 185,636 people reported side effects after taking Lipitor. Among them, 243 people $(0.13 \%)$ had Dementia Alzheimer's type. The lower incidence of Alzheimer's dementia in the Flonase group compared to the Lipitor group was significant $(p<0.001$, Fisher exact test, two tailed).

Conclusion: Long term use of oral non-steroidal anti-inflammatory drugs (NSAIDs) is linked with reduced risk of developing Alzheimer's disease. Data from MedWatch suggest that fluticasone propionate administered intranasally might have a similar preventive effect to ibuprofen. Perhaps combining ibuprofen and Flonase could be therapeutic. Further studies would be desirable.
\end{abstract}

Keywords: Alzheimer's disease, brain, dementia, intranasal, steroids

Studies of Alzheimer's disease suggest that neuroinflammation [1] or deranged brain wound healing [2] may be responsible for some cases. Injury to the brain from trauma or irradiation may initiate the process [3]. The characteristic pathologic plaques and tangles are a non-specific result of the disease process, not a cause [4].

Biochemical and neuropathological studies of brains from individuals with Alzheimer's disease

\footnotetext{
${ }^{*}$ Correspondence to: Steven Lehrer, MD, Box 1236 Radiation Oncology, Mount Sinai Medical Center, 1 Gustave L. Levy Place, New York, NY 10029, USA. E-mail: stevenlehrer@hotmail.com.
}

provide clear evidence for an activation of inflammatory pathways and glial inflammation [5]. If part of the neuroinflammation is autoimmune, the predominance of Alzheimer's disease in women could be explained, since autoimmune diseases are much more common in women than men.

However, there is no beneficial effect of nonsteroidal anti-inflammatory drugs (NSAIDs), such as naproxen, rofecoxib, or ibuprofen, on cognition or overall Alzheimer's disease severity. Oral NSAIDs have no value as an Alzheimer's disease treatment [6].

Chou et al. showed a reduction in risk of Alzheimer's disease in rheumatoid arthritis patients 
on prednisone [7]; unadjusted the effect is almost significant $(p=0.1)$. The reduction is quite remarkable, given the tiny amounts of prednisone that reach the brain after an oral dose due to tight plasma protein binding. Balis et al. found that the cerebrospinal fluid/plasma ratio of dexamethasone is 0.15 , of prednisolone 0.079 [8]. Such minute amounts of steroid in the brain presumably have a tiny or negligible effect. Indeed, another placebo controlled study showed no effect at all on Alzheimer's disease of low dose oral prednisone after one year [9].

Introducing the steroid directly into the hippocampus and rhinencephalon via the nose, as happens in hay fever subjects, could be more effective. In the present study, we analyzed FDA MedWatch data for intranasal fluticasone propionate (Flonase) to determine the frequency of Alzheimer's disease as an adverse event reported after use of the medication.

\section{METHODS}

We used data from MedWatch, the Food and Drug Administration (FDA) Safety Information and Adverse Event Reporting Program [10]. MedWatch was organized in 1993 to collect data regarding adverse events in healthcare. An adverse event is any undesirable experience associated with the use of a medical product. The MedWatch system collects reports of adverse reactions and quality problems, primarily due to drugs and medical devices, but also for other FDA-regulated products (e.g., dietary supplements, cosmetics, medical foods, and infant formulas).

MedWatch offers a choice between a voluntary reporting form, designed primarily for health care professionals and the general public, and a mandatory adverse event reporting service (AERS) form, available to manufacturers, importers, and medical product user facilities that manage and store medical products. The latter group is required by law to submit the mandatory form immediately upon discovery of a product malfunction. Printable mail-in forms are available as an alternative to the online submission system [11].

A MedWatch report of an adverse event does not establish causation. For any given report, there is no certainty that the drug in question caused the reaction. The adverse event may have been related to the underlying disease being treated, perhaps caused by another drug being taken concurrently, or something else.
Machine-readable data from MedWatch, including adverse drug reaction reports from manufacturers, are part of a public database. We used the online tool eHealthMe to query the database $[12,13]$. Data are exclusively from MedWatch, not from social media [14].

\section{RESULTS}

By September 20, 2017, 35,221 people reported side effects to FDA after taking Flonase (intranasal fluticasone propionate). Among them, 9 people $(0.03 \%)$ had Dementia Alzheimer's type (Fig. 1).

By October 3, 2017, 185,636 people reported side effects after taking Lipitor (atorvastatin). Among them, 243 people $(0.13 \%)$ had Dementia Alzheimer's type (Fig. 1). In a large-scale randomized controlled trial evaluating statin therapy as a treatment for mild to moderate Alzheimer disease, atorvastatin was not associated with significant clinical benefit over 72 weeks [15].

By October 8, 2017, 102,006 people reported side effects when taking Ibuprofen. Among them, 34 people $(0.03 \%)$ had Dementia Alzheimer's type, a proportion identical to Flonase (Fig. 1). Ibuprofen reduces the risk of Alzheimer's disease, although, as was mentioned, it is not a treatment [16].

The lower incidence of Alzheimer's dementia in the Flonase group compared to the Lipitor group was significant $(p<0.001$, Fisher exact test, two tailed).

$80 \%$ of the people taking Flonase were over 60; 93\% of the people taking Lipitor were over $60 ; 89 \%$ of the people taking ibuprofen were over 60 (Table 1 ). $89 \%$ of the patients using Flonase were female, versus $56 \%$ of the patients taking Lipitor and $82 \%$ of the patients taking ibuprofen. The most common other conditions in patients who reported Alzheimer's disease are listed in Table 2. Drugs most often used by patients who reported Alzheimer's disease are listed in Table 3. Additional side effects in patients who reported Alzheimer's disease are listed in Table 4.

\section{DISCUSSION}

One case control study demonstrated that hay fever and other allergies were associated with diminished risk of Alzheimer's disease (odds ratio 0.6) [17]. Hay fever patients' use of nasal glucocorticoids might be lessening their risk of Alzheimer's disease and functioning as a treatment in early cases. Another analysis found no effect of hay fever [18], but subjects' use 


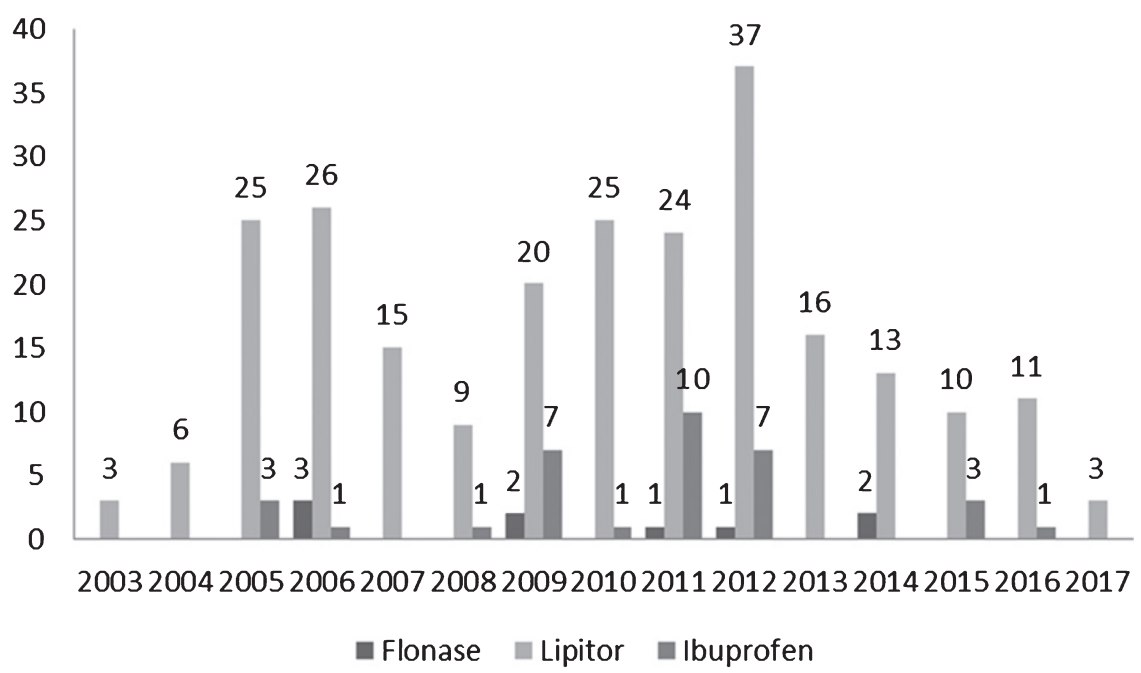

Fig. 1. MedWatch Alzheimer's disease reports in patients using Flonase, Lipitor (atorvastatin), and ibuprofen by year. Number of reports is above the corresponding bar.

of anti-allergy anticholinergics, such as diphenhydramine, may have confused the results by raising risk of Alzheimer's disease [19].

Both pregnenolone and progesterone arrive in the brain after nasal administration [20]. Intranasal regular insulin improves cognition in Alzheimer's disease, probably because of its brain effects [21]; and the kinetics of intranasal ACTH suggest that it gets into the brain [22]. Therefore, intranasal fluticasone probably gets into the brain via the nose, as well.

The rodent hippocampus is particularly sensitive to glucocorticoids. While glucocorticoids are essential for an effective stress response, their oversecretion was originally hypothesized to contribute to age-related hippocampal degeneration. However, conflicting findings were reported on whether prolonged exposure to elevated glucocorticoids endangered the hippocampus; and whether the primate hippocampus, where Alzheimer's disease originates, even responds to glucocorticoids as the rodent hippocampus does [23].

Our use of adverse event drug reports has distinct problems. One problem is that the analysis does not include all those taking Flonase, ibuprofen or Lipitor who did not have any adverse reaction (including Alzheimer's disease) to any drug they were taking. This problem might be addressed by prescription records (or company sales records) indicating how many took the drug. A big data approach could involve a large national database sample from Taiwan or South Korea, tracking medication usage and later medical diagnoses.
Table 1

Age distribution of patients using Flonase, Lipitor, or ibuprofen

\begin{tabular}{lccc}
\hline Age & Flonase & Lipitor & Ibuprofen \\
\hline $10-19$ & 0 & $0.63 \%$ & $3.70 \%$ \\
$20-29$ & 0 & $0.00 \%$ & $0.00 \%$ \\
$30-39$ & 0 & $0.63 \%$ & $3.70 \%$ \\
$40-49$ & 0 & $0.00 \%$ & $0.00 \%$ \\
$50-59$ & $20 \%$ & $5.70 \%$ & $3.70 \%$ \\
$60+$ & $80 \%$ & $93.04 \%$ & $88.89 \%$ \\
\hline
\end{tabular}

Another problem in our analysis is that those who reported adverse effects were likely also taking other medications, which may be associated with Alzheimer's disease, either increasing or decreasing the risk (some because they treat a disease that is a risk factor for Alzheimer's disease). This problem might be addressed more systematically by a big data analysis of MedWatch to seek drugs negatively associated with Alzheimer's disease. However, it is implausible that the patterns of other medications in our analysis were the same for those taking Flonase, ibuprofen, and Lipitor.

In a previous study, Lerner et al. found that delirium is an initial symptom in about $3 \%$ of patients diagnosed with Alzheimer's disease [24]. Medications are one of the biggest causes of delirium, especially benzodiazepines [25], which were common in patients taking atorvastatin as a concurrent medication. Dementia has been listed as a side effect of atorvastatin (and other statins), but might represent the confluence of two common disorders: hypercholesterolemia and dementia (which is not the same as Alzheimer's disease). 
Table 2

Most common other conditions in patients who reported Alzheimer's disease

\begin{tabular}{lll}
\hline Flonase & Lipitor & Ibuprofen \\
\hline Trigeminal Neuralgia (1 person, 11.11\%) & Sleep Disorder (13 people, 5.35\%) & Rheumatoid Arthritis (7 people, 20.59\%) \\
Sinus Disorder (1 person, 11.11\%) & Depression (9 people, 3.70\%) & Preventive Health Care (6 people, 17.65\%) \\
Metastases To Spine (1 person, 11.11\%) & Diabetes (8 people, 3.29\%) & Osteoporosis (4 people, 11.76\%) \\
High Blood Pressure (1 person, 11.11\%) & Osteoporosis (7 people, 2.88\%) & Multiple Myeloma (4 people, 11.76\%) \\
Depression (1 person, 11.11\%) & Ill-Defined Disorder (7 people, 2.88\%) & Chronic Obstructive Pulmonary Disease \\
& & (4 people, 11.76\%) \\
\hline
\end{tabular}

Table 3

Other drugs most commonly used by patients who reported Alzheimer's disease

\begin{tabular}{lll}
\hline Flonase & Lipitor & Ibuprofen \\
\hline Aspirin (4 people, $44.44 \%)$ & Aricept (47 people, 19.34\%) & Aspirin (14 people, 41.18\%) \\
Zometa (3 people, 33.33\%) & Aspirin (21 people, 8.64\%) & Lorazepam (10 people, 29.41\%) \\
Lasix (3 people, 33.33\%) & Namenda (20 people, 8.23\%) & Humira (9 people, 26.47\%) \\
Calcium (3 people, 33.33\%) & Plavix (14 people, 5.76\%) & Norvasc (8 people, 23.53\%) \\
Albuterol (3 people, 33.33\%) & Nexium (13 people, 5.35\%) & Cymbalta (7 people, 20.59\%) \\
\hline
\end{tabular}

Table 4

Other common side effects in patients who reported Alzheimer's disease

\begin{tabular}{lll}
\hline Flonase & Lipitor & Ibuprofen \\
\hline Pneumonia (5 people, 55.56\%) & Memory Loss (55 people, 22.63\%) & Fall (9 people, 26.47\%) \\
Pain (5 people, 55.56\%) & Stroke (24 people, 9.88\%) & Breathing Difficulty (8 people, 23.53\%) \\
Headache (5 people, 55.56\%) & Depression (21 people, 8.64\%) & Memory Loss (7 people, 20.59\%) \\
Gastroesophageal Reflux Disease (5 people, 55.56\%) & Diarrhea (20 people, 8.23\%) & Drug Ineffective (7 people, 20.59\%) \\
Fall (5 people, 55.56\%) & Pneumonia (18 people, 7.41\%) & Injury (6 people, 17.65\%) \\
\hline
\end{tabular}

It is possible that individuals already suffering some degree of dementia would be less bothered by seasonal rhinitis or have less access to over the counter drugs such as fluticasone nasal spray. These phenomena could account for part of the observed lower incidence of Dementia Alzheimer's type reports in patients using Flonase ${ }^{\circledR}$.

Nevertheless, long term use of oral non-steroidal anti-inflammatory drugs is linked with reduced risk of developing Alzheimer's disease [26]. These drugs also potentially inhibit brain wound healing [2]. We posit that NSAIDS and steroids both inhibit wound healing in the brain (a well-known fact in the periphery). We further suggest that the lower incidence of AD due to NSAIDS and steroids may be through inhibiting brain wound healing. That is, there is an initial event, and the brain response is what causes the dementia which we call "Alzheimer's disease." NSAIDS and steroids may be preventive through a wound healing inhibition mechanism. Our hypothesis is consistent with the idea that amyloid and tau and their cascade of pathology are both a brain response linked to the genesis of the problem [4].

In summary, data from MedWatch presented here suggest that fluticasone propionate administered intranasally might have a similar preventive effect to ibuprofen. Glucocorticoids, moreover, inhibit wound healing. Perhaps combining ibuprofen and Flonase could be therapeutic. Further studies would be desirable.

\section{CONFLICT OF INTEREST}

The authors have no conflict of interest to report.

\section{REFERENCES}

[1] McManus RM, Heneka MT (2017) Role of neuroinflammation in neurodegeneration: New insights. Alzheimers Res Ther $9,14$.

[2] Lehrer S, Rheinstein PH (2016) A derangement of the brain wound healing process may cause some cases of Alzheimer's disease. Discov Med 22, 43-46.

[3] Lehrer S, Rheinstein PH, Rosenzweig KE (2017) Association of radon background and total background ionizing radiation with Alzheimer's disease deaths in U.S. states. J Alzheimers Dis 59, 737-741.

[4] Castellani RJ, Perry G (2014) The complexities of the pathology-pathogenesis relationship in Alzheimer disease. Biochem Pharmacol 88, 671-676.

[5] D'Andrea MR, Cole GM, Ard MD (2004) The microglial phagocytic role with specific plaque types in the Alzheimer disease brain. Neurobiol Aging 25, 675-683.

[6] Miguel-Alvarez M, Santos-Lozano A, Sanchis-Gomar F, Fiuza-Luces C, Pareja-Galeano H, Garatachea N, Lucia A 
(2015) Non-steroidal anti-inflammatory drugs as a treatment for Alzheimer's disease: A systematic review and meta-analysis of treatment effect. Drugs Aging 32, 139-147.

[7] Chou RC, Kane M, Ghimire S, Gautam S, Gui J (2016) Treatment for rheumatoid arthritis and risk of Alzheimer's disease: A nested case-control analysis. CNS Drugs 30, 1111-1120.

[8] Balis FM, Lester CM, Chrousos GP, Heideman RL, Poplack DG (1987) Differences in cerebrospinal fluid penetration of corticosteroids: Possible relationship to the prevention of meningeal leukemia. J Clin Oncol 5, 202-207.

[9] Aisen PS, Davis KL, Berg JD, Schafer K, Campbell K, Thomas RG, Weiner MF, Farlow MR, Sano M, Grundman M, Thal LJ (2000) A randomized controlled trial of prednisone in Alzheimer's disease. Alzheimer's Disease Cooperative Study. Neurology 54, 588-593.

[10] Kessler DA (1993) Introducing MEDWatch. A new approach to reporting medication and device adverse effects and product problems. JAMA 269, 2765-2768.

[11] Craigle V (2007) MedWatch: The FDA safety information and adverse event reporting program. J Med Libr Assoc 95, 224.

[12] US Department of Health and Human Services eHealthMe study from FDA and social media reports [electronic source]. http://www.ehealthme.com/print/ds15829624

[13] Salihoglu M, Turhan V, Onem Y, Ulcay A, Uzun G, Ay H (2013) Sudden hearing loss in a patient receiving piperacillin/tazobactam and daptomycin for diabetic foot infection. Scand J Infect Dis 45, 239-240.

[14] Coloma PM, Becker B, Sturkenboom MC, van Mulligen EM, Kors JA (2015) Evaluating social media networks in medicines safety surveillance: Two case studies. Drug Saf 38, 921-930.

[15] Feldman HH, Doody RS, Kivipelto M, Sparks DL, Waters DD, Jones RW, Schwam E, Schindler R, Hey-Hadavi J, DeMicco DA, Breazna A (2010) Randomized controlled trial of atorvastatin in mild to moderate Alzheimer disease: LEADe. Neurology 74, 956-964.

[16] Vlad SC, Miller DR, Kowall NW, Felson DT (2008) Protective effects of NSAIDs on the development of Alzheimer disease. Neurology 70, 1672-1677.

[17] Shalat SL, Seltzer B, Pidcock C, Baker Jr EL (1987) Risk factors for Alzheimer's disease: A case-control study. $\mathrm{Neu}$ rology 37, 1630-1633.
[18] Breteler MM, van Duijn CM, Chandra V, Fratiglioni L, Graves AB, Heyman A, Jorm AF, Kokmen E, Kondo K, Mortimer JA, et al. (1991) Medical history and the risk of Alzheimer's disease: A collaborative re-analysis of casecontrol studies. EURODEM Risk Factors Research Group. Int J Epidemiol 20(Suppl 2), S36-S42.

[19] Risacher SL, McDonald BC, Tallman EF, West JD, Farlow MR, Unverzagt FW, Gao S, Boustani M, Crane PK, Petersen RC, Jack Jr CR, Jagust WJ, Aisen PS, Weiner MW, Saykin AJ, Alzheimer's Disease Neuroimaging Initiative (2016) Association between anticholinergic medication use and cognition, brain metabolism, and brain atrophy in cognitively normal older adults. JAMA Neurol 73, 721-732.

[20] Ducharme N, Banks WA, Morley JE, Robinson SM, Niehoff ML, Mattern C, Farr SA (2010) Brain distribution and behavioral effects of progesterone and pregnenolone after intranasal or intravenous administration. Eur J Pharmacol 641, 128-134.

[21] Craft S, Claxton A, Baker LD, Hanson AJ, Cholerton B, Trittschuh EH, Dahl D, Caulder E, Neth B, Montine TJ, Jung Y, Maldjian J, Whitlow C, Friedman S (2017) Effects of regular and long-acting insulin on cognition and Alzheimer's disease biomarkers: A pilot clinical trial. J Alzheimers Dis 57, 1325-1334.

[22] Lehrer S, Rheinstein P (2015) Two compartment model of MSH/ACTH may be a surrogate for intranasal insulin central nervous system kinetics. https://www.j-alz.com/ content/two-compartment-model-mshacth-may-besurrogate-intranasal-insulin-central-nervous-system

[23] Conrad CD (2008) Chronic stress-induced hippocampal vulnerability: The glucocorticoid vulnerability hypothesis. Rev Neurosci 19, 395-411.

[24] Lerner AJ, Hedera P, Koss E, Stuckey J, Friedland RP (1997) Delirium in Alzheimer disease. Alzheimer Dis Assoc Disord 11, 16-20.

[25] Clegg A, Young JB (2011) Which medications to avoid in people at risk of delirium: A systematic review. Age Ageing 40, 23-29.

[26] Wyss-Coray T, Rogers J (2012) Inflammation in Alzheimer disease-a brief review of the basic science and clinical literature. Cold Spring Harb Perspect Med 2, a006346. 